\title{
Chemoselective nickel-catalyzed coupling through substrate photoexcitation
}

\author{
Pradipta Das, ${ }^{a}$ Eliot F. Woods, ${ }^{a}$ Jack T. Ly, ${ }^{\mathrm{b}, \mathrm{c}}$ Jack N. Olding, ${ }^{\mathrm{d}}$ Kayla F. Presley,,c Brennan Romanoff, ${ }^{\mathrm{e}}$ Tod A. \\ Grusenmeyer, ${ }^{b}$ Emily A. Weiss, ${ }^{\text {a,d,f }}$ and Julia A. Kalow*a
}

\begin{abstract}
Metallaphotoredox catalysis combines the well-established mechanisms of transition-metal-catalyzed cross-coupling reactions with one-electron redox manipulations enabled by light. In most cases, a transition metal or organic dye serves as the photoredox catalyst while a ground-state $\mathrm{Pd}$ or Ni catalyst performs the organometallic steps. Cross-coupling mechanisms that rely on direct photoexcitation of a lightabsorbing substrate have the potential to access distinct mechanisms and deliver unique selectivity based on the substrate's excited-state properties. In this report, we describe a photoinduced, Ni-catalyzed Suzuki-Miyaura cross coupling reaction that selectively functionalizes BODIPY chromophores, a versatile class of tunable, bright, photostable fluorophores. Using a bis-iodo BODIPY substrate, the selectivity for mono- vs. bis-arylation was found to be governed by a remote substituent that subtly alters the excited-state properties of the substrate. Consistent with a substrate photoexcitation mechanism, high chemoselectivity is also observed in mixtures of chromophores with distinct excited-state properties. This reaction is compatible with a variety of substituted BODIPY chromophores and boronic acids and esters, enabling the rapid synthesis of unsymmetrically-substituted chromophores.
\end{abstract}

\section{INTRODUCTION}

The introduction of light to transition-metal-catalyzed crosscoupling reactions has enabled new transformations and accelerated known reactions of challenging substrates. ${ }^{1}$ In metallaphotoredox catalysis, a photoredox catalyst engages in single-electron transfer (SET) with the substrate and/or transition-metal cocatalyst to generate radical intermediates or change oxidation states, respectively. More recently, many examples of light-driven crosscoupling reactions without a photoredox catalyst have been reported (Figure 1). ${ }^{2-7}$ The proposed role of light is direct photoexcitation of a catalyst such as $\operatorname{Pd}(0)$, which significantly lowers the barrier for oxidative addition by accessing one-electron mechanisms or facilitating challenging reductive eliminations (Figure 1a). ${ }^{8}$ While photoexcitation of a catalyst - be it a photoredox catalyst or a lowvalent Pd or Ni catalyst - can activate it towards SET with a groundstate aryl halide substrate, ${ }^{9-11}$ in principle, photoexcitation of the organic substrate should also induce SET with a ground-state catalyst. However, typical organic substrates do not absorb visible light, so previous approaches that employ substrate photoexcitation rely on deprotonation (Figure $\mathbf{1 b})^{2,4}$ or electron donor-acceptor (EDA) complexation (Figure 1c) ${ }^{12,13}$ to induce reactivity. We envisioned that direct substrate photoexcitation could enable the selective functionalization of organic chromophores, a class of compounds with myriad applications. Here, we show that visiblelight photoexcitation of halogenated boron-dipyrromethene (BODIPY) chromophores enables Ni-catalyzed Suzuki-Miyaura cross-coupling reactions under mild conditions (Figure 1d). These conditions are selective for the BODIPY substrate in the presence of aryl iodides that do not absorb visible light. Moreover, the substrate photoexcitation mechanism exhibits high chemoselectivity correlated to the photophysics of the substrate. (a) light-driven carbonylation (Arndtsen, 2020)

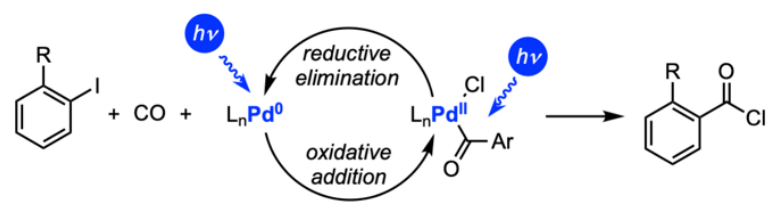

(b) light-driven amination (Fu and Peters, 2017)

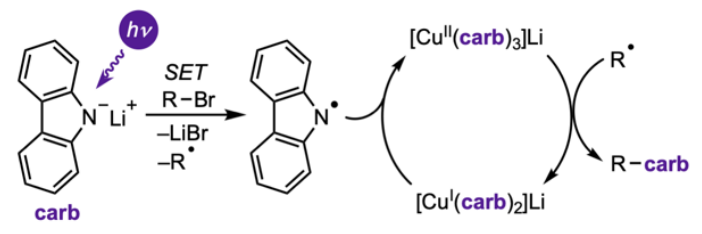

(c) deaminative cross-coupling (Koh, 2021)

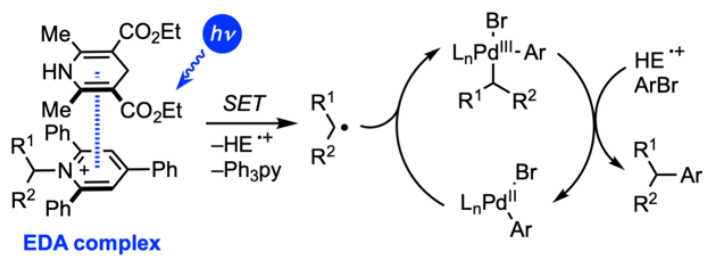

(d) this work: light-driven cross-coupling of chromophores

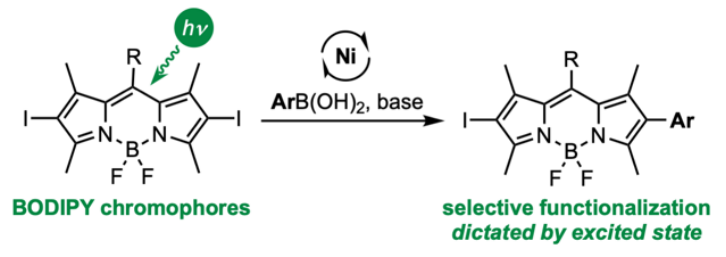

Figure 1. Examples of light driving transition-metal-catalyzed (a) carbonylation, (b) amination, and (c) deaminative cross-coupling in the absence of photoredox catalysts. In this work (d), chromophores can be selectively functionalized through substrate photoexcitation. $\mathrm{HE}=$ Hantzsch ester. 
Organic chromophores are commonly used as photoredox catalysts because of their low cost and synthetic tunability. ${ }^{14}$ In isolated cases, light-absorbing substrates and products have been shown to act as photoredox catalysts to mediate their own functionalization or formation through SET. ${ }^{15-17}$ We imagined that the same excited-state properties that make a chromophore an effective photoredox catalyst-high triplet yields, long excited-state lifetimes, and high excited-state redox potentials — could be used to engage a ground-state transition-metal catalyst in a photoinduced cross-coupling. A key advantage of metallophotoredox crosscoupling mechanisms is accessing the reactivity of one-electron chemistry while bypassing unselective free radical intermediates. ${ }^{18}$ We hypothesized that photoexcitation of the substrate could induce SET with the transition-metal catalyst to enter a reaction manifold with not just lower barriers, but with distinct selectivity compared to thermal cross-coupling conditions. Such a photoinduced crosscoupling reaction could exhibit selectivity in the presence of multiple substrates with similar sterics or electronics but distinct excited-state properties.

In this work, we show that the photoinduced $\mathrm{Ni}$-catalyzed crosscoupling of diiodo-BODIPY chromophores is mild and selective. These conditions are not only selective for the BODIPY substrate in the presence of aryl halides that do not absorb visible light, but are also highly selective for mono vs. bis addition. Mono-substituted products may be further elaborated by thermal cross-coupling reactions to yield donor-acceptor BODIPYs. Strikingly, small structural changes at the meso position that do not affect the sterics or electrophilicity of the C-I bond result in selective formation of the bis-substituted product. This selectivity is consistent with a substrate photoexcitation mechanism that involves SET to the triplet state. Finally, we show that a mixture of halogenated BODIPYs with similar absorption spectra undergo selective photoinduced cross-coupling, in contrast to a thermal reaction that delivers a complex mixture of products. This result suggests that substrate photoexcitation mechanisms can confer unique selectivity on cross-coupling reactions, potentially enabling the identification of triplet sensitizers and photooxidants from mixtures of halogenated chromophores.

\section{RESULTS AND DISCUSSION}

\section{Reaction development}

We turned our initial focus to halogenated BODIPY chromophores as substrates for the photoinduced cross-coupling reaction. This selection was guided by the broad utility of BODIPY derivatives as photosensitizers and photocatalysts for transformations including oxidations, ${ }^{19,20}$ oxidative couplings, ${ }^{21-23}$ cross coupling, ${ }^{24}$ atom transfer radical addition, ${ }^{25}$ and photopolymerization. ${ }^{26,27}$ Furthermore, BODIPYs are ubiquitous fluorophores in materials science and bioimaging due to large absorption coefficients, narrow emission profiles, high photoluminescence quantum yields, and good photostability. ${ }^{28}$ Derivatives that access the triplet state are additionally useful for photodynamic therapy ${ }^{29}$ and triplet-triplet annihilation upconversion. ${ }^{30,31}$ The photophysical and chemical properties of BODIPYs are highly tunable using modifications to the core. Representative examples include red-shifting the absorption and emission to the near-infrared, ${ }^{32}$ increasing the Stokes shift, ${ }^{28}$ increasing intersystem crossing to the triplet state, ${ }^{33}$ shifting the redox potentials, ${ }^{34}$ and inducing responses to viscosity ${ }^{35}$ and small molecules. $^{36}$

We hypothesized that the identity of the halogen on the BODIPY electrophile would strongly affect cross-coupling reactivity by virtue of its effect on $\mathrm{C}-\mathrm{X}$ bond strength, redox potential, and photophysics. In cross-coupling reactions, the rate of oxidative addition typically follows the trend $\mathrm{I}>\mathrm{Br}>\mathrm{Cl}$. Similarly, the identity and quantity of halogens is expected to strongly influence the BODIPY excited state. Halogenated BODIPY chromophores are frequently used as triplet photosensitizers thanks to the internal heavy-atom effect, ${ }^{37-40}$ and the same trend $(\mathrm{I}>\mathrm{Br}>\mathrm{Cl})$ is observed for intersystem crossing efficiency $\left(\Phi_{\text {ISC }}\right) .{ }^{41}$ If the substrate reacts in its excited state, we also expect to see an effect of the meso substituent on BODIPY. This substituent significantly affects the singlet excited-state lifetime and rate of decay by nonradiative internal conversion through the free rotor effect. ${ }^{35,42}$

Therefore, we began our reaction development with diiodoBODIPY chromophore 1, a known photosensitizer ${ }^{37}$ and photocatalyst $^{43}$ that absorbs green light. We found promising reactivity with $\mathrm{Ni}$ catalysts, which are commonly employed in metallophotoredox reactions due to their propensity for singleelectron chemistry. ${ }^{4-47}$ Multiple mechanisms have been proposed for the role of light in these reactions, including oxidation-state modulation by a photoredox catalyst, ${ }^{48-51}$ direct photoexcitation of $\mathrm{Ni}$ (II) complexes, ${ }^{52}$ and recovery of inactive, off-cycle $\mathrm{Ni}$ (II) species by photoreduction. ${ }^{53,54}$ Under the optimized conditions, 1 underwent Suzuki-Miyaura cross-coupling at room temperature under irradiation with green light in the presence of $\mathrm{Ni}(\mathrm{dppp}) \mathrm{Cl}_{2}$ precatalyst. Even though excess 4-methoxyphenyl boronic acid (2) was used, mono-substituted BODIPY 3 a was selectively formed in $82 \%$ yield (Table 1 , entry 1 ). No bis-substituted product $3 \mathrm{~b}$ could be detected in the crude reaction mixture by LCMS or ${ }^{1} \mathrm{H}$ NMR. This chemoselectivity is notable in comparison to traditional thermal Pd-catalyzed conditions (entry 2), which favor the bissubstituted product $\mathbf{3 b}$. To confirm the role of light and catalyst for the photoinduced conditions, we performed several control reactions. No product was observed in the absence of Ni catalyst (entry 3 ), and $10 \%$ yield was obtained when the reaction was conducted in the dark (entry 4$)$. Under thermal conditions $\left(78^{\circ} \mathrm{C}\right)$ in the dark, both $\mathbf{3 a}$ and $\mathbf{3 b}$ were observed in low yield and in nearly equal quantities (entry 5), suggesting that the photoinduced reaction achieves selectivity through a distinct mechanism. Intriguingly, substituting $\mathrm{Ni}(\mathrm{dppp}) \mathrm{Cl}_{2}$ with $\mathrm{Pd}(\mathrm{OAc})_{2} / \mathrm{dppp}$ under the optimal photoinduced conditions also delivered $\mathbf{3 a}$ as the major product, albeit with lower yield and selectivity, suggesting that the mechanism governing mono-selectivity could be general for different transition-metal catalysts. 
Table 1. Optimization for the nickel-catalyzed photoinduced Suzuki-Miyaura reaction

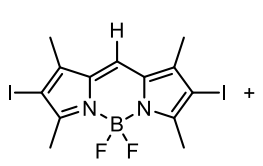

1

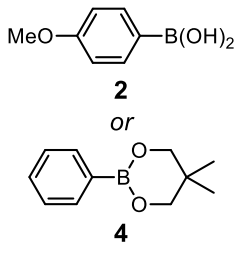

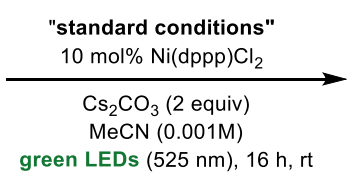

green LEDs (525 nm), $16 \mathrm{~h}, \mathrm{rt}$

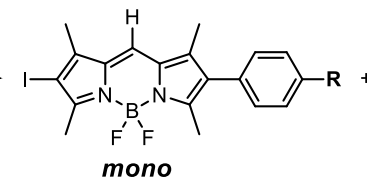

mono

$5 a(R=H)$

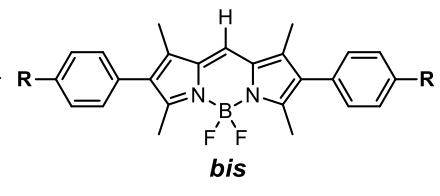

3b $(\mathrm{R}=\mathrm{OMe})$

5b $(\mathrm{R}=\mathrm{H})$

\begin{tabular}{|c|c|c|c|c|c|}
\hline nucleophile & entry & deviation from "standard conditions" & $\%$ conversion & $\%$ yield $^{b}$ & mono:bis \\
\hline \multirow{6}{*}{2} & 1 & none (Condition $\mathbf{A})$ & 100 & 82 & $>15: 1$ \\
\hline & 2 & $10 \% \mathrm{Pd}\left(\mathrm{PPh}_{3}\right)_{4}, \mathrm{Na}_{2} \mathrm{CO}_{3}$, dioxane- $\mathrm{H}_{2} \mathrm{O}, 100^{\circ} \mathrm{C}$, no light & 89 & 57 & $1: 8$ \\
\hline & 3 & no $\mathrm{Ni}(\mathrm{dppp}) \mathrm{Cl}_{2}$ & 12 & $<5$ & - \\
\hline & 4 & no light & 26 & 10 & $>15: 1$ \\
\hline & 5 & $78^{\circ} \mathrm{C}$, no light & 49 & 14 & $1: 1.3$ \\
\hline & 6 & $\begin{array}{c}10 \mathrm{~mol} \% \mathrm{Ni}(\mathrm{COD})_{2}, 12 \mathrm{~mol} \% \text { of }\left(\mathrm{PCy}_{2}\right)_{2} \text { ethane, toluene-dioxane } \\
\text { (Condition B) }\end{array}$ & 97 & 61 & $12: 1$ \\
\hline $\begin{array}{l}\text { phenyl boronic } \\
\text { acid }\end{array}$ & 7 & none (Condition A) & 36 & 17 & $>15: 1$ \\
\hline \multirow{3}{*}{4} & 8 & Condition B & 78 & 63 & $>15: 1$ \\
\hline & 9 & no $\mathrm{Ni}(\mathrm{COD})_{2}$ or no ligand & $15-20$ & $<5$ & - \\
\hline & 10 & no light & 26 & 11 & $>15: 1$ \\
\hline
\end{tabular}

${ }^{a}$ All data represent the average of two experiments. Under the standard conditions, the reaction was performed on a $0.004 \mathrm{mmol} s \mathrm{scale}$, with 2 equiv cesium carbonate, 10 equiv of 4-methoxyboronic acid, 0.1 equiv of $\mathrm{Ni}(\mathrm{dppp}) \mathrm{Cl}_{2}$, and degassed acetonitrile (0.001 M). Irradiation was provided by green LEDs using fan cooling to maintain a temperature of $<30^{\circ} \mathrm{C}$. See SI for details. ${ }^{\mathrm{b}}$ Conversion, yield, and ratio of mono to bis products were determined by LCMS using Erythrosine-B as external standard.

When we sought to expand the nucleophile scope to electronneutral boronic acids, disappointingly, the standard conditions (Condition A) delivered low yields of cross-coupled product (entry 7). Therefore, the catalyst, ligand, solvent, and nucleophile were reevaluated. We found that a combination of $\mathrm{Ni}(\mathrm{COD})_{2}$ and $\left(\mathrm{PCy}_{2}\right)_{2}$ ethane ligand in a mixed solvent of toluene and dioxane, using the neopentyl glycol ester 4, yields the desired phenylsubstituted BODIPY chromophore 5a in 63\% yield with high chemoselectivity (entry 8 , Condition B). Other bisphosphine ligands such as dppe and dppp also provide good yields (SI, Table S6). We repeated the key control reactions using these modified conditions and again saw no product in the absence of catalyst and $11 \%$ yield in the absence of light (entries 9 and 10), consistent with a Ni-catalyzed, light-promoted reaction. Condition B is also applicable to electron-rich boronic acids, albeit with slightly lower yield and chemoselectivity (entry 6).
We hypothesized that green LEDs (centered at $525 \mathrm{~nm}$, FWHM 30 nm; SI, Figures S9-S13) would promote the reaction with the highest efficiency due to the substrate's maximum absorbance at $531 \mathrm{~nm}$. To test this hypothesis, we performed the reaction with LEDs ranging from $U V(350 \mathrm{~nm})$ to red $(626 \mathrm{~nm})$. As expected, based on the absorption spectrum of 1 , under both Condition $\mathrm{A}$ and $\mathrm{B}$, green LEDs yielded the desired product in the highest yield. Identical reactions with UV, violet, and red LEDs resulted in low conversions with no desired product, and blue, yellow, and white ${ }^{55}$ LEDs provided low yields of product (Figure 2). The sensitivity of this reaction to the color of the light further suggests that a thermal reaction is not responsible for catalysis. Other components of the reaction, such as the boronic acid/ester and the Ni precatalyst, do not absorb green light, also supporting the hypothesis that the BODIPY substrate or derivative thereof is involved in the light-dependent step. 


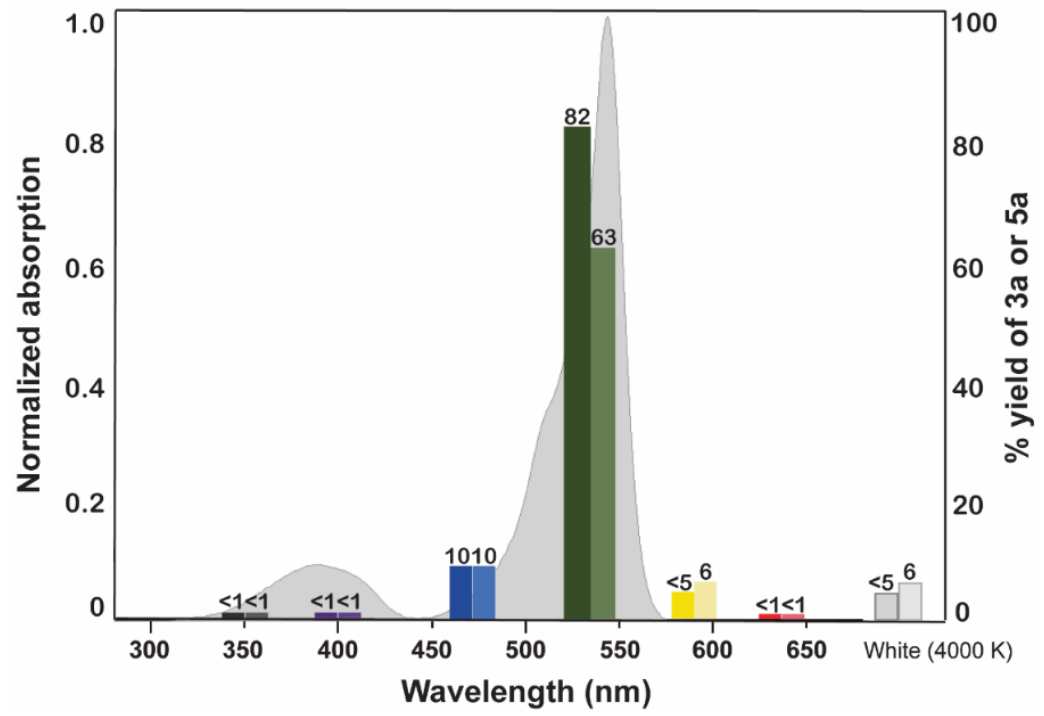

Figure 2. Wavelength screen for the photoinduced nickel-catalyzed Suzuki-Miyaura reaction between BODIPY 1 and boronic acid $\mathbf{2}$ under Condition A (dark bars), or boronic ester 4 under Condition B (faded bars). The normalized UV-Vis absorption spectrum of BODIPY 1 is superimposed in the background. See SI for details.

\section{Substrate scope}

Based on our optimization studies in Table 1, we next explored the scope of the photoinduced cross-coupling reaction with respect to boronic acid/ester coupling partner. On preparative scale, it was possible to increase the concentration to $0.01 \mathrm{M}$ without sacrificing yield or chemoselectivity (see SI, Table S2 and S5 for details). Using Condition A, electron-rich aromatic, heteroaromatic, and vinyl boronic acids provided the mono-functionalized products in 30 $80 \%$ isolated yield. Minor bis-substituted products were only observed in the crude reaction mixture when using 5-membered heteroaromatic boronic acids (13 and 14, 6-8:1). Azide- and alkyne-substituted boronic acids furnished BODIPYs 16 and 17 with handles for conjugation by $\mathrm{Cu}$-catalyzed click chemistry. Under Condition B, electron-neutral and -poor boronic esters provided mono-substituted products in $32-63 \%$ isolated yield, accompanied by unreacted starting material (8-25\%); the modest reactivity of electron-poor nucleophiles remains a limitation of this method (Table 2).
Table 2. Nucleophile scope for the photoinduced nickel-catalyzed Suzuki-Miyaura reaction ${ }^{\mathrm{a}}$

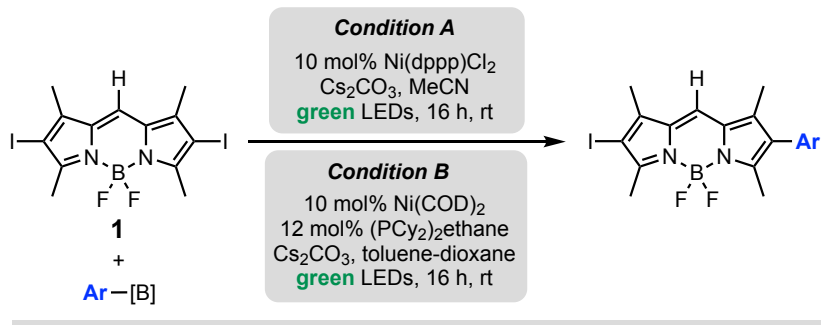

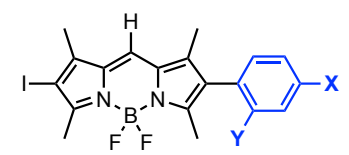

3a $(X=O M e, Y=H): 78 \%(A)$

5a $(X=H, Y=H): 63 \%(B)$

$6(X=S M e, Y=H): 30 \%(A)$

$7\left(\mathrm{X}=\mathrm{NMe}_{2}, \mathrm{Y}=\mathrm{H}\right): 80 \%(A)$

$8(\mathrm{X}=\mathrm{OMe}, \mathrm{Y}=\mathrm{F}): 31 \%(A)$

$9(X=H, Y=O M e): 73 \%(A)$

$10\left(\mathrm{X}=\mathrm{CH}_{3}, \mathrm{Y}=\mathrm{H}\right): 48 \%(B)$

$11(\mathrm{X}=\mathrm{Cl}, \mathrm{Y}=\mathrm{H}): 53 \%(B)$

$12\left(X=\mathrm{CF}_{3}, \mathrm{Y}=\mathrm{H}\right): 32 \%(B)$

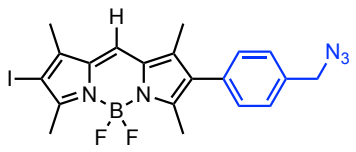

16: $52 \%(A)$

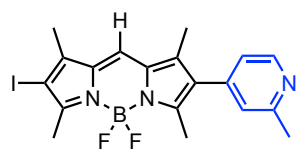

18: $43 \%(B)$

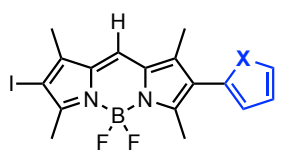

$13(X=0): 46 \%(A)^{b}$

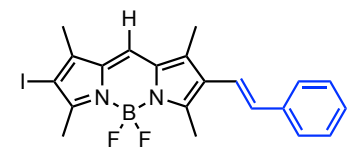

15: $61 \%(A)$

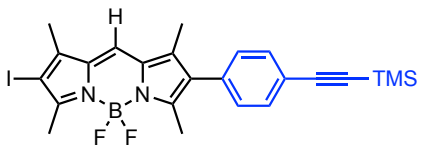

17: $63 \%(A)$

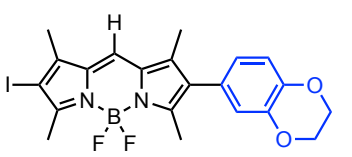

19: $67 \%(A)$
$14(\mathrm{X}=\mathrm{S}): 50 \%(A)^{c}$

${ }^{a}$ Reactions were performed on a $0.024 \mathrm{mmol}$ scale, with 2 equiv cesium carbonate, 10 equiv boronic acid/ester, and 0.1 equiv $\mathrm{Ni}($ dppp $) \mathrm{Cl}_{2}$ in degassed acetonitrile $(0.01 \mathrm{M})$ for Condition $\mathrm{A}$, or 0.1 equiv $\mathrm{Ni}(\mathrm{COD})_{2}$ and 0.12 equiv $\left(\mathrm{PCy}_{2}\right)_{2}$ ethane in degassed toluenedioxane $(1: 1,0.01 \mathrm{M})$ for Condition $\mathrm{B}$, under irradiation by green $\mathrm{LEDs}$ 
with fan cooling to maintain $<30{ }^{\circ} \mathrm{C}$. Products were purified by flash column chromatography. ${ }^{b}$ The crude reaction mixture was a $6.7: 1$ ratio of mono:bis products. ${ }^{c}$ The crude reaction mixture was a 8.2:1 ratio of mono:bis products.

The high chemoselectivity of the photoinduced reaction stands in contrast to typical thermal cross-coupling conditions. The selective activation of $\mathrm{C}-\mathrm{X}$ bonds in polyhalogenated aromatic and heteroaromatic substrates is most often based on intrinsic reactivity differences between sites on the (hetero)aromatic scaffold ${ }^{56,57}$ or between $\mathrm{C}-\mathrm{X}$ bonds (i.e., $\mathrm{I}>\mathrm{Br}>\mathrm{Cl}$ ) ${ }^{58-60}$ In Pd-catalyzed crosscoupling reactions of polyhalogenated (hetero)aromatics, the identity of the ligand can be used to enhance or even invert the substrate's intrinsic selectivity. ${ }^{59}$ For substrates with multiple identical C-X bonds, however, a statistical mixture is often observed, even when equimolar amounts of the nucleophile are used. Monoselectivity can only be achieved if the first substitution deactivates the remaining $\mathrm{C}-\mathrm{X}$ bonds through steric or electronic effects, ${ }^{61}$ or causes a significant change in crystallinity (solvent-free conditions). ${ }^{62}$

In our light-dependent reaction, the mono-substituted products are deactivated towards the photoinduced cross-coupling, but not to thermal conditions. Thus, the remaining C-I bond can be engaged in thermal cross-coupling reactions to deliver unsymmetrically substituted BODIPY chromophores, which are found in dyads and triads designed for light harvesting, nonlinear optics, and bioconjugation. ${ }^{33,63-67}$ To highlight the utility of this strategy, we applied our protocol to the construction of BODIPYs containing electron donors and acceptors at the 2 and 6 positions. The conventional route to prepare such donor-acceptor BODIPYs relies on sequential mono-halogenation, cross-coupling, halogenation, and cross-coupling, rendering this stepwise sequence inefficient (10\% overall yield).$^{68}$ In contrast, the photoinduced cross-coupling of diiodo-BODIPY 1 with an electron-rich (donor) arylboronic acid selectively delivers the mono-substituted product ( $3 \mathbf{a}$ or 7 ) in high yield. This intermediate can be directly elaborated with an electronpoor (acceptor) boronic acid using traditional thermal, Pd-catalyzed cross-coupling conditions (Scheme 1). This route was used to prepare donor-acceptor BODIPYs 20 and 21 in $40-45 \%$ overall yield over 3 steps from the commercial laser dye BODIPY 505/515 (CAS 21658-70-8). Thus, the photoinduced cross-coupling protocol improves synthetic access to unsymmetrically substituted BODIPYs for material applications.
Scheme 1. Synthesis of unsymmetrical BODIPY chromophores by photoinduced cross-coupling.

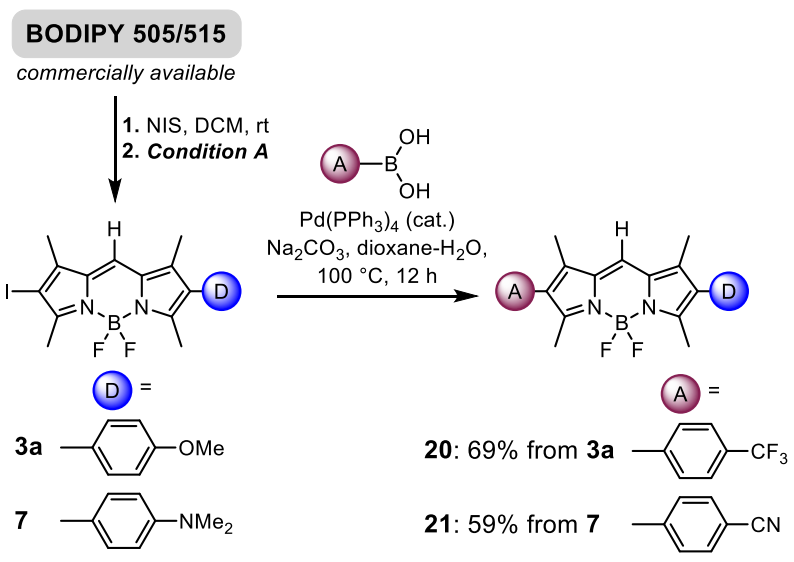

Next, we explored the scope of this cross-coupling with respect to the BODIPY substrate (Table 3). Diiodo-BODIPYs containing methyl, phenyl, or para-substituted aryl groups at the meso position all provided the mono-substituted products in $34-72 \%$ yield, using Condition A for electron-rich boronic acids $(22,24,26)$ and Condition B for electron-neutral and -poor boronic esters $(23,25)$. Surprisingly, placing a sterically hindered mesityl substituent at the meso position (BODIPY 28) altered the chemoselectivity of the photoinduced cross-coupling. Under the standard conditions (16 h), exclusively bis-substituted product $29 \mathrm{~b}$ was observed and isolated in $72 \%$ yield. By running the reaction to incomplete conversion $(5 \mathrm{~h})$, we could obtain a $1: 2$ ratio of mono- to bissubstituted products and isolate 29 a in $32 \%$ yield. These results suggest that mesityl-BODIPY $\mathbf{2 8}$ continues to react after the initial mono-substitution, unlike the other chromophores studied. Bissubstitution was also observed for the reaction of $\mathbf{2 8}$ with other boronic acids and esters under Conditions $\mathrm{A}$ and $\mathrm{B}(\mathbf{3 0}, \mathbf{3 1})$. 
Table 3. BODIPY scope for the photoinduced nickel-catalyzed Suzuki-Miyaura reaction ${ }^{2}$
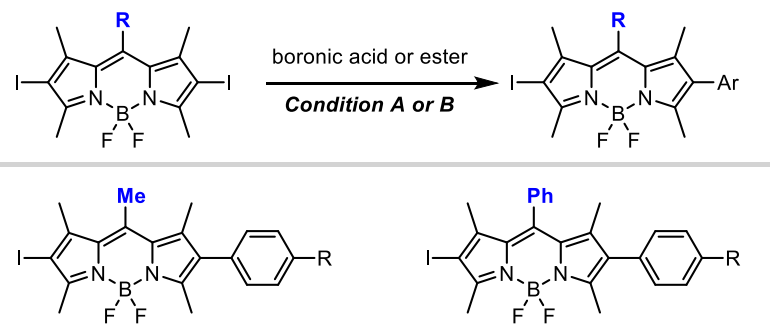

$22(\mathrm{R}=\mathrm{OMe}): 67 \%(A)$

$23(\mathrm{R}=\mathrm{H}): 46 \%(B)$

$24(\mathrm{R}=\mathrm{OMe}): 57 \%(A)$

$25(\mathrm{R}=\mathrm{CN}): 39 \%(B)$

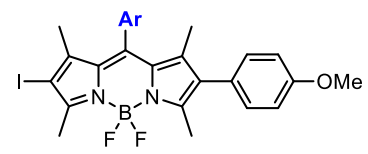

$26\left(\mathrm{Ar}=p-\mathrm{MeOC}_{6} \mathrm{H}_{4}\right): 72 \%(A)$ $27\left(\mathrm{Ar}=p-\mathrm{NCC}_{6} \mathrm{H}_{4}\right): 51 \%(B)$

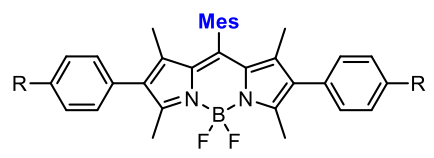

29b $(\mathrm{R}=\mathrm{OMe}): 72 \%(A)$

$30(\mathrm{R}=\mathrm{H}): 47 \%(B)$

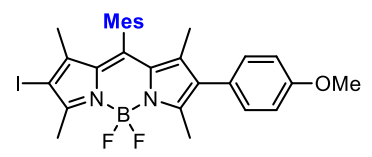

29a: $32 \%(A)^{b}$

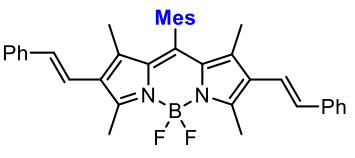

31: $72 \%(A)$

${ }^{\text {a }}$ Reactions were performed on a $0.024 \mathrm{mmol}$ scale, with 2 equiv cesium carbonate, 10 equiv boronic acid, and 0.1 equiv $\mathrm{Ni}(\mathrm{dppp}) \mathrm{Cl}_{2}$ in degassed acetonitrile $(0.01 \mathrm{M})$ for Condition $\mathrm{A}$, or 0.1 equiv $\mathrm{Ni}(\mathrm{COD})_{2}$ and 0.12 equiv $\left(\mathrm{PCy}_{2}\right)_{2}$ ethane in degassed toluene-dioxane $(1: 1,0.01$ $\mathrm{M})$ for Condition $\mathrm{B}$, under irradiation by green LEDs with fan cooling to maintain $<30{ }^{\circ} \mathrm{C}$. Products were purified by flash column chromatography. ${ }^{\mathrm{b}}$ The reaction was stopped after $5 \mathrm{~h}$.

Finally, we sought to determine whether chromophores with redshifted absorption can undergo the photoinduced cross-coupling with even lower-energy light. Aza-BODIPYs are red-shifted relative to BODIPYs due to the electronegative $\mathrm{N}$ atom lowering the energy of the LUMO. ${ }^{69}$ This effect, in combination with electron-rich aryl substituents, results in chromophores that absorb in the red to nearIR ranges. ${ }^{70,71}$ Halogenated aza-BODIPYs have been used as photosensitizers for singlet oxygen generation ${ }^{72,73}$ and photoredox catalysts for radical polymerization ${ }^{26}$. We found that aza-BODIPY $32\left(\lambda_{\max }=658 \mathrm{~nm}\right)$ underwent photoinduced Suzuki-Miyaura crosscoupling to deliver mono-substituted product 33 in $28 \%$ yield (Scheme 2). Future work will include the optimization of photoinduced cross-coupling conditions for these red-shifted substrates.

\section{Scheme 2. Cross-coupling of aza-BODIPY with red light ${ }^{\mathrm{a}}$}

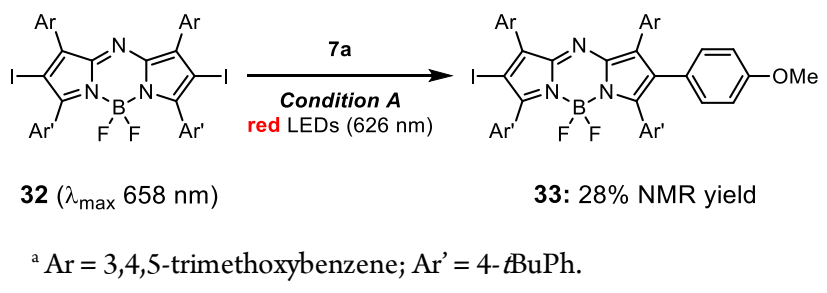

In summary, we have discovered that diiodo-BODIPY and azaBODIPY chromophores undergo Ni-catalyzed coupling when irradiated with light corresponding to their absorption maxima. However, while all BODIPY substrates evaluated exhibit similar absorption and emission profiles (SI, Figure S18), their reactivity patterns differ significantly. Therefore, to better understand the selectivity of the photoinduced cross-coupling reaction, we probed the nature of the light dependence and the photophysical and photochemical properties of the substrates in greater detail.

\section{Photoinitiation vs. photocontrol}

Figure 2 shows that the optimal wavelengths of the photoinduced cross-coupling correspond to the absorption of the BODIPY substrate. We sought to establish whether the reaction is photoinitiated or photocontrolled. If the reaction is photoinitiated, product formation should continue in the dark after a period of initial irradiation. We monitored the conversion of 1 under Condition $\mathrm{A}$ as a function of time during alternating green irradiation and dark. During the periods with green irradiation, we saw significant conversion of $\mathbf{1}$ to mono-substituted product $\mathbf{3 a}$. During the dark periods, we continued to see conversion of 1 but minor formation of $3 a$ ( $<5 \%$ yield in 5 hours), consistent with the unproductive background decomposition that occurs in the dark (Table 1, entry 4). The difference in the rate of product formation between the irradiated and dark periods suggests that some thermal background reaction can occur in the dark, representing less than one catalyst turnover, but the productive reaction is significantly accelerated (and the decomposition suppressed) under irradiation.

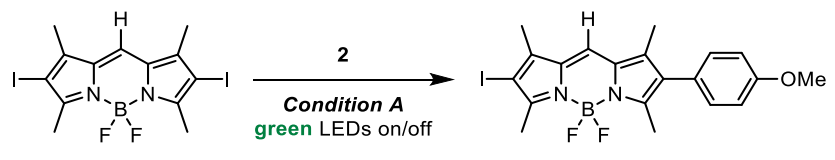

$3 a$

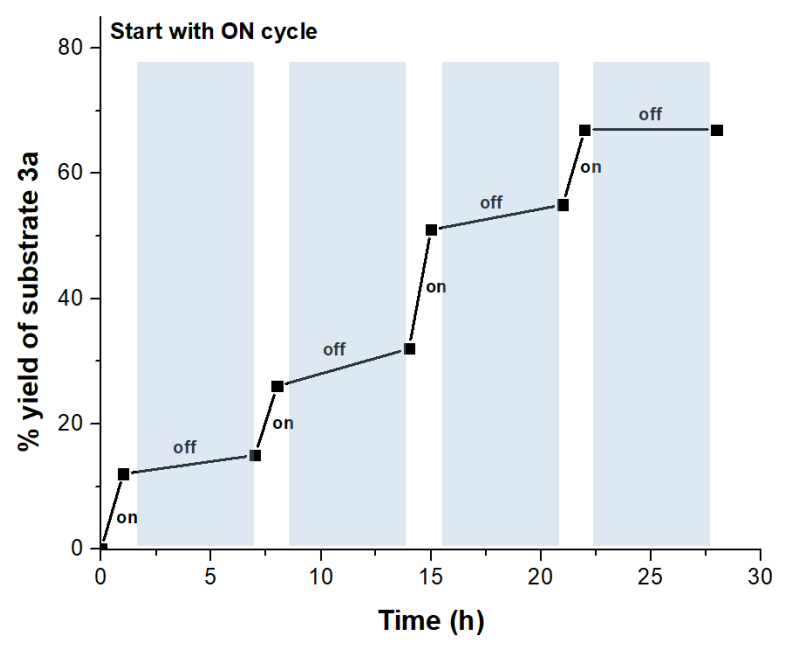

Figure 3. On/off experiment with BODIPY 1 under Condition A. Measurements were taken at an interval of $1 \mathrm{hr}$ for the ON cycle and 6 hrs for OFF cycle. See SI for details.

\section{Excited-state properties of the substrates and products}

To rationalize the observed reactivity and selectivity under irradiation wavelengths corresponding to substrate absorption, we next turned our attention towards the excited-state properties of the BODIPY substrates. Since the identity and number of halogens is expected to significantly influence excited-state properties, ${ }^{40}$ we also 
prepared dibromo-BODIPY 34 and monoiodo-BODIPY 35. Under Conditions $\mathrm{A}$ and $\mathrm{B}$, neither $\mathbf{3 4}$ nor $\mathbf{3 5}$ formed any detectable crosscoupled product. While the inertness of 34 could be explained by the lower reactivity of $\mathrm{C}-\mathrm{Br}$ bonds towards oxidative addition, the absence of reactivity for 35 , which only differs from substrate 1 by one iodine atom, suggests a photophysical or photochemical origin for selectivity.

We compared these unreactive substrates to 1 , its monosubstituted product 3a, and mesityl-BODIPY 28, which forms bissubstituted $29 \mathrm{~b}$ via intermediate $29 \mathrm{a}$. We reasoned that the conversion of $\mathbf{1}$ to $\mathbf{3 a}$ must be accompanied by a significant change in its photophysical or photochemical properties, which prevent further cross-coupling to form $\mathbf{3 b}$. We also anticipated that $3 \mathrm{a}$ might have similar properties to 35 , which was also unreactive despite absorbing green light. In contrast, we expected that 28 and 29a should possess similar excited-state properties, explaining why the reaction continues after the first cross-coupling to form $29 \mathrm{~b}$.

For these compounds, we measured the ground-state absorption spectra, steady-state fluorescence spectra, fluorescence lifetimes $\left(\tau_{\mathrm{s}}\right)$, fluorescence quantum yields $\left(\Phi_{\mathrm{FL}}\right)$, and intersystem crossing quantum yields $\left(\Phi_{\text {ISC }}\right)$. The collection of these data permitted the calculation of the radiative decay rate constant $\left(k_{\mathrm{r}}\right)$, the nonradiative decay rate constant $\left(k_{\mathrm{nr}}\right)$, and the intersystem crossing rate constant $\left(k_{\text {isc }}\right)$. The photochemical and photophysical data are summarized in Table 4; additional data are shown in Table S9 and representative datasets are illustrated in Figures S17-S23 (SI).

Table 4. Excited-state properties of BODIPY chromophores

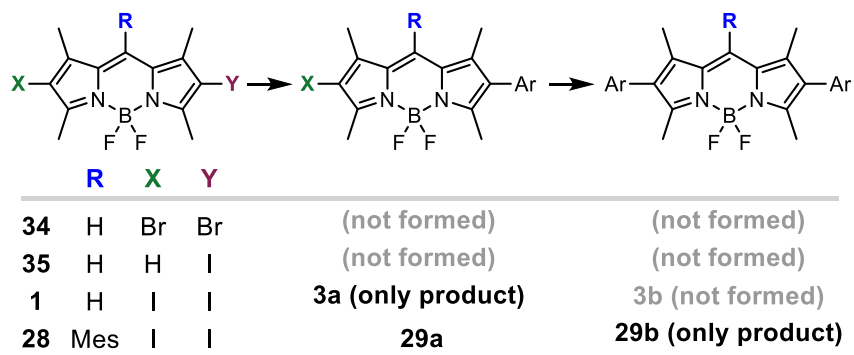

\begin{tabular}{|c|c|c|c|c|c|c|c|c|c|c|c|c|}
\hline compound & $\lambda_{\mathrm{abs}}{ }^{\mathrm{a}}$ & $\lambda_{e m}{ }^{a}$ & $\begin{array}{c}\tau s \\
(n s)^{b}\end{array}$ & $\tau_{\mathrm{T}}(\mu \mathrm{s})^{\mathrm{c}}$ & $\Phi_{\mathrm{F}}^{\mathrm{d}}$ & $\Phi_{\Delta}^{\mathrm{e}}$ & $\begin{array}{c}\mathbf{k}_{\mathbf{r}} \\
\left(10^{8} \mathrm{~s}^{-1}\right)\end{array}$ & $\begin{array}{c}\mathbf{k}_{\mathrm{nr}} \\
\left(10^{8} \mathrm{~s}^{-1}\right)\end{array}$ & $\begin{array}{c}\mathbf{k}_{\text {isc }} \\
\left(10^{8} \mathrm{~s}^{-1}\right)\end{array}$ & $\mathrm{E}_{\text {red }}(\mathrm{V})^{\mathrm{f}}$ & $\mathrm{E}_{\mathrm{T}}(\mathrm{eV})^{\mathrm{g}}$ & $\begin{array}{l}\mathrm{E}_{\text {red,T }} \\
(\mathrm{V})^{\mathrm{h}}\end{array}$ \\
\hline 34 & 538 & 551 & 1.70 & n.d. & 0.22 & 0.67 & 1.30 & 0.65 & 3.94 & -1.29 & 1.59 & 0.30 \\
\hline 35 & 525 & 539 & 0.23 & 1.8 & 0.03 & 0.84 & 1.30 & 5.65 & 36.5 & -1.43 & 1.57 & 0.14 \\
\hline 1 & 532 & 553 & 0.31 & 2.1 & 0.02 & 0.94 & 0.65 & 3.23 & 28.4 & -1.30 & 1.55 & 0.25 \\
\hline $3 a$ & 530 & 601 & 0.62 & 3.1 & 0.05 & 0.45 & 0.82 & 8.20 & 7.38 & -1.40 & 1.58 & 0.18 \\
\hline 28 & 531 & 548 & 0.29 & $0.85,53.4 \%$ & 0.02 & 0.87 & 0.67 & 4.33 & 28.3 & -1.35 & 1.64 & 0.29 \\
\hline $29 a$ & 528 & 585 & 0.67 & 6.7 & 0.06 & 0.62 & 0.90 & 4.78 & 9.25 & -1.40 & 1.63 & 0.23 \\
\hline
\end{tabular}

${ }^{\mathrm{a}} \mathrm{Unit}=\mathrm{nm}$, concentration $=1.0 \times 10^{-5} \mathrm{M}$ in acetonitrile. ${ }^{\mathrm{b}} \tau_{\mathrm{S}}=$ Fluorescence lifetime in nanoseconds, measured by time-resolved photoluminescence (concentration $=1.0 \times 10^{-6} \mathrm{M}$ in acetonitrile). Fluorescence lifetime data were fit to a mono-exponential decay. ${ }^{c} \tau_{\mathrm{T}}=$ Triplet lifetime in microseconds, measured by microsecond transient absorption in toluene (concentration $=1.0 \times 10^{-6} \mathrm{M}$ in acetonitrile). ${ }^{\mathrm{d}} \Phi_{\mathrm{F}}=$ Absolute fluorescence quantum yields determined by integrating sphere (concentration $=1.0 \times 10^{-6} \mathrm{M}$ in acetonitrile). ${ }^{\mathrm{e}} \Phi_{\Delta}=$ Phosphorescence quantum yield of singlet oxygen $\left({ }^{1} \mathrm{O}_{2}\right)$ phosphorescence with phenazine as standard. ${ }^{g}$ Onset potentials shown in V. All electrochemical measurements were performed in acetonitrile (0.1 M $n-\mathrm{Bu}_{4} \mathrm{NPF}_{6}$ ) using $\mathrm{Ag} / \mathrm{AgCl}$ wire as a pseudo-reference electrode and referenced to ferrocene/ferrocenium redox couple. ${ }^{\mathrm{h}}$ Triplet energies were determined by $\lambda_{\max }$ of the phosphorescence spectrum at $77 \mathrm{~K}$ in $2: 2: 1: 1$ (v:v) ethyl iodide/diethyl ether/ethanol/toluene. See SI for spectra. ${ }^{\mathrm{h}}$ Approximated as $\mathrm{E}_{\mathrm{red}, \mathrm{T}}=\mathrm{E}_{\mathrm{T}}+\mathrm{E}_{\text {red. }}$.

The normalized ground-state absorption and steady-state fluorescence spectra of chromophores 34, 35, 1, 3a, 28 and 29a were collected in acetonitrile, representative of Condition A (SI, Figure S17). The absorption spectra of all six derivatives are similar, exhibiting maxima between 525 and $538 \mathrm{~nm}$ and narrow absorption transitions with high extinction coefficients and vibronic progression characteristic of $\pi-\pi^{*}$ transitions. The similarities suggest that differences in the absorption are not responsible for the changes in reactivity. The fluorescence spectra of all chromophores are also assigned as $\pi-\pi^{*}$ in nature, but the mono-substituted products $3 \mathbf{a}$ and 29a exhibit larger Stokes shifts and broader emission than the initial substrates, suggesting charge-transfer character in their singlet $\pi-\pi^{*}$ excited states.
The singlet excited-state dynamics in these molecules are influenced by their halogen content, arylation at the 6-position, and the nature of the substituent in the meso position. The dibromoBODIPY 34 exhibits the highest fluorescence quantum yield (0.22). All of the iodinated chromophores possess low fluorescence quantum yields (0.02-0.11) and fluorescence lifetimes under a nanosecond, suggesting that the singlet excited state is too shortlived to undergo bimolecular reactions. Therefore, intersystem crossing (ISC) to a long-lived triplet state is likely responsible for the observed reactivity. ISC is the dominant kinetic pathway in both of the diiodo-BODIPY derivatives (1 and 28 ) and mono-iodoBODIPY 35. These compounds have similar ISC crossing rate 
constants on the order of $3 \times 10^{9} \mathrm{~s}^{-1}$, resulting in quantum yields for ISC exceeding 0.8 .

Coupling installs an aryl group that increases possible nonradiative decay pathways by vibration, rotation, and intramolecular charge transfer. ${ }^{7-76}$ Correspondingly, the mono-functionalized derivatives $3 a$ and $29 a$ exhibit higher rates of both radiative and nonradiative decay, compared to their diiodo-BODIPY precursors. However, the meso substituents have an impact on the relative magnitude of the changes that occur after cross-coupling. Both 3a and 29a experience a decrease in ISC rate and quantum yield compared to their precursors. In $\mathbf{3} \mathbf{a}$, the rate of nonradiative decay $\left(8.2 \times 10^{8} \mathrm{~s}^{-1}\right)$ becomes competitive with ISC $\left(7.4 \times 10^{8} \mathrm{~s}^{-1}\right)$; in contrast, for 29a, ISC remains twice as fast compared to nonradiative decay $\left(9.2 \times 10^{8} \mathrm{~s}^{-1}\right.$ vs. $\left.4.7 \times 10^{8} \mathrm{~s}^{-1}\right)$. Compared to smaller substituents, the mesityl group is particularly effective at decreasing internal conversion by limiting the free rotor effect. ${ }^{42,77}$ Nevertheless, these differences in ISC cannot fully explain the difference in reactivity between $3 a$ and 29 a because mono-iodo-BODIPY 35 exhibits high quantum yield and rate for ISC, but does not undergo cross-coupling. Furthermore, all of the iodinated BODIPYs measured had triplet lifetimes $0.85 \mu$ s or greater, and we did not observe any trend between triplet lifetime and reactivity. These data suggest that formation of a triplet state is a necessary precondition to reactivity but not the basis for mono vs. bis chemoselectivity.

Since iodo-BODIPYs are competent photoredox catalysts, ${ }^{43}$ we next evaluated the photochemical reactivity of the triplet states. The ground-state redox potentials were determined by cyclic voltammetry (SI, Figures S1-S7 and S14-S15), and the triplet energies $\left(\mathrm{E}_{\mathrm{T}}\right)$ were determined by phosphorescence measurements in a solvent glass at $77 \mathrm{~K}$ (SI, Figures S23). The excited-state oxidation potentials fell between -0.68 and $-0.82 \mathrm{vs}$. $\mathrm{Fc} / \mathrm{Fc}^{+}$(SI, Table S9) and did not reveal any trends consistent with the reactivity: that is, unreactive product $\mathbf{3 a}$ has a similar excited-state oxidation potential to reactive intermediate $29 \mathrm{a}(-0.80$ and -0.82 $\mathrm{V})$, and unreactive substrate $35(-0.73 \mathrm{~V})$ is a better excited-state reductant than substrate $1(-0.68 \mathrm{~V})$. However, the excited-state reduction potentials reveal a clear cutoff between reactive substrates $(1,28,29 \mathrm{a} \geq 0.23 \mathrm{~V})$ and unreactive substrates $(35,3 \mathrm{a} \leq 0.18 \mathrm{~V})$. This $70 \mathrm{mV}$ difference in excited-state reduction potentials corresponds to a $1.61 \mathrm{kcal} / \mathrm{mol}$ difference in thermodynamic driving force for electron transfer.

Taken together, we find that the photoinduced cross-coupling reaction is exquisitely sensitive to the excited-state properties of the substrate. The reaction is capable of distinguishing between substrates with similar absorption, sterics, and electronics, based on subtly different excited-state reduction potentials. The observed trends are consistent with the substrate triplet state acting as a photooxidant for oxidative addition by $\mathrm{SET}^{45}$ or oxidation-state modulation of a Ni intermediate ${ }^{48-51}$ or off-cycle species. ${ }^{54}$ However, our data do not rule out scenarios that involve photoexcitation of $\mathrm{Ni}$ BODIPY complexes. ${ }^{52}$

Three representative scenarios in which photoexcitation of the substrate or a $\mathrm{Ni}$ complex derived from it promote the crosscoupling cycle are presented in Figure 4. In scenario (a), an example of oxidation-state modulation, ${ }^{3} \mathrm{BODIPY}$ oxidizes an on-cycle $\mathrm{Ni}$ (II) intermediate, forming a $\mathrm{Ni}(\mathrm{III})$ intermediate that undergoes facile reductive elimination. In scenario (b), ${ }^{3}$ BODIPY undergoes SET with $\mathrm{Ni}(0)$ to form an ion pair, which undergoes collapse to the oxidative addition product in a photoinduced variation of the classic mechanism elucidated by Kochi. ${ }^{45}$ Alternatively, in scenario (c), photoexcitation of a $\mathrm{Ni}$ (II)-BODIPY adduct is required for catalytic turnover.

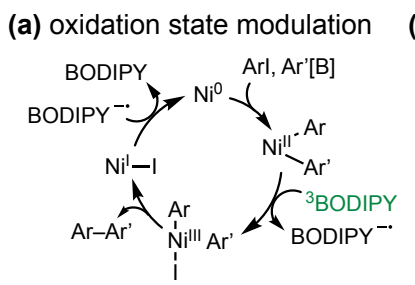

(b) photoinduced oxidative addition

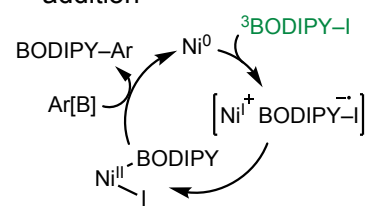

(c) organometallic photoexcitation

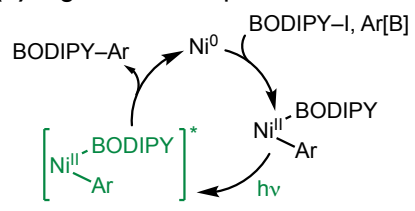

Figure 4. Representative possible mechanisms that involve photoexcitation of BODIPY or an organometallic intermediate. For simplicity, inorganic byproducts are not included.

\section{Selectivity of the photoinduced reaction with mixtures of substrates}

If scenario (a) is operative, the substrate that undergoes crosscoupling need not be photoactive. In that scenario, the BODIPY substrate can be viewed as a photoredox catalyst that should, in principle, be able to promote the cross-coupling of other groundstate substrates in concert with Ni catalysis. To test this hypothesis, we performed competition experiments between 1 and substrates that do not undergo photoinduced cross-coupling. First, we examined the chemoselectivity of the photoinduced cross-coupling in the presence of a simple aryl halide, 2-fluoroiodobenzene (36), which does not absorb past $300 \mathrm{~nm}$ (SI, Figure S24). While 36 undergoes efficient Suzuki-Miyaura cross-coupling under thermal conditions with various Pd catalysts, ${ }^{78}$ in a competition experiment between 1 and 36 (1:10 molar ratio) under Condition $A$, we observed exclusive formation of $\mathbf{3 a}$ arising from mono-arylation of 1 (Scheme 3). By ${ }^{19}$ F NMR, we observed neither conversion of 36 nor formation of the expected biphenyl product (SI, Figure S25).

Scheme 3. Competition experiment between BODIPY 1 and $4-$ fluoroidobenzene
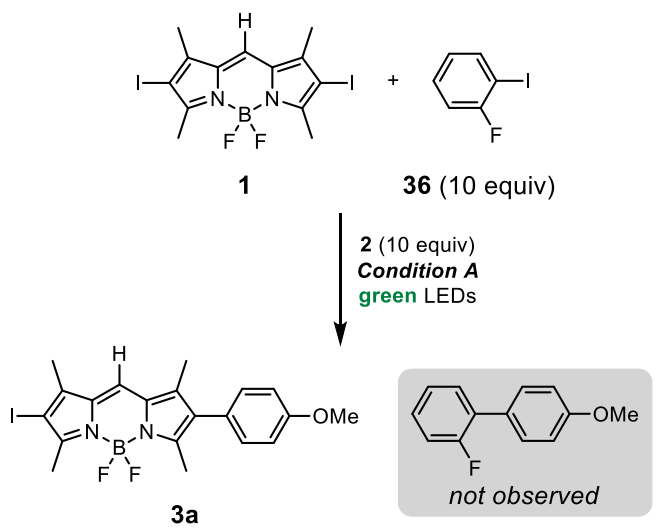

Next, we sought to test the chemoselectivity of this reaction in the presence of multiple substrates with similar absorption but different excited-state properties. A 1:1:1 mixture of 1, 34, and 35 was subjected to Condition A with excess arylboronic acid (Scheme 4). Again, only the monosubstituted product 3 a derived from 1 could be observed by ${ }^{1} \mathrm{H}$ NMR and high-resolution mass spectrometry; 34 and 35 were recovered unreacted (SI, Figures S26-29). Under 
standard thermal Pd-catalyzed conditions, a complex mixture of products arising from 1, 34, and $\mathbf{3 5}$ is observed (SI, Figure S30).

Scheme 4. Competition experiment between BODIPYs ${ }^{a}$

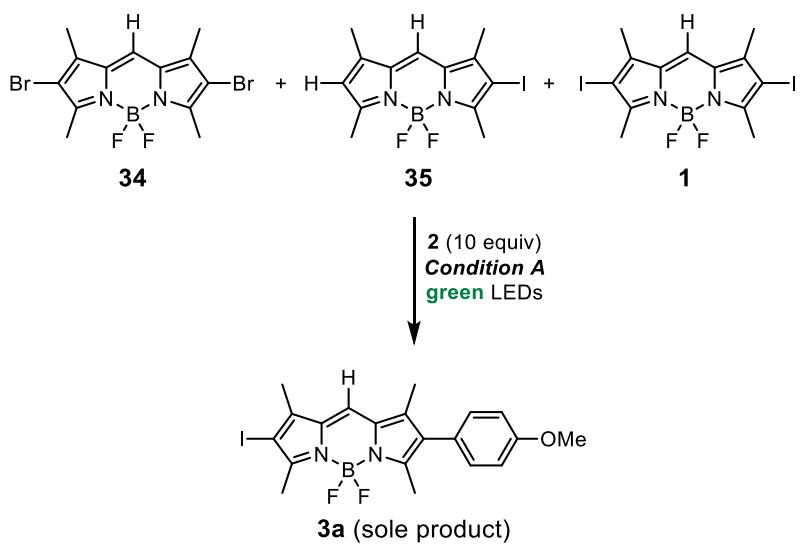

${ }^{a}$ Reactions were performed on a $0.004 \mathrm{mmol}$ scale, with 1:1:1 ratio of 1, 34, and 35, 2 equiv $\mathrm{Cs}_{2} \mathrm{CO}_{3}, 10$ equiv boronic acid, and 0.1 equiv $\mathrm{Ni}(\mathrm{dppp}) \mathrm{Cl}_{2}$ in degassed acetonitrile $(0.001 \mathrm{M})$ under irradiation by green LEDs with fan cooling to maintain $\angle 30^{\circ} \mathrm{C}$. Conversion, yield, and ratio of starting materials to products were determined by ${ }^{1} \mathrm{H}-\mathrm{NMR}$ using dibromomethane as external standard.

Therefore, we can rule out mechanistic scenarios in which the BODIPY chromophore acts as a photoredox catalyst or photosensitizer $^{79}$ to activate on- or off-cycle intermediates towards cross coupling (for example, Figure 4a). At this stage, we cannot distinguish between mechanisms in which photoexcited BODIPY substrates enter the catalytic cycle (Figure $\mathbf{4 b}$ ) and mechanisms in which an organometallic intermediate containing BODIPY is photoexcited (Figure 4c). The isolation and characterization relevant organometallic intermediates to explore this latter possibility are ongoing. Beyond providing insight into the role of substrate photoexcitation in the reaction mechanism, these competition experiments demonstrate that chemoselectivity for the substrate with most efficient ISC and highest excited-state reduction potential is maintained in mixtures of chromophores with similar absorption characteristics.

\section{CONCLUSIONS}

We have developed a photoinduced, Ni-catalyzed SuzukiMiyaura cross-coupling of halogenated BODIPY chromophores. This reaction exhibits high chemoselectivity depending on the identity of the meso substituent. For diiodo-BODIPY substrates with small groups at the meso position, high chemoselectivity is observed for the mono-functionalized product, providing rapid synthetic access to unsymmetrically substituted BODIPYs. Preliminary results demonstrate that this reactivity can be extended to bathochromically-shifted chromophores such as aza-BODIPYs using red light. Substitution at the meso position of diiodo-BODIPY with a mesityl group does not perturb the $\mathrm{C}-\mathrm{I}$ bonds sterically or electronically, but shifts the reactivity to selective bis-substitution. Comparison of the excited-state properties of reactive and unreactive substrates reveals a cutoff in the excited-state reduction potential that is correlated to reactivity.

We propose that the cross-coupling mechanism involves photoexcitation of the chromophore substrate or an organometallic intermediate derived from it because the optimal wavelengths for reactivity correspond to the substrate absorption. Based on competition experiments, we can rule out scenarios in which the substrate acts as a photoredox catalyst or photosensitizer. In addition to applications to chromophore synthesis, we envision that the photoinduced cross-coupling will enable the discovery of new triplet sensitizers and photoredox catalysts from complex mixtures of chromophores. Such a goal will require us to broaden the scope of this reaction to classes beyond BODIPY and aza-BODIPY. Efforts to realize this reactivity-driven approach to materials discovery and detailed mechanistic investigations of the organometallic mechanism are underway in our lab.

\section{ASSOCIATED CONTENT}

\section{Supporting Information}

Experimental procedures; characterization data for all new compounds; excited-state spectroscopic methods and data (PDF).

\section{AUTHOR INFORMATION}

Corresponding Authors

Julia A. Kalow - Department of Chemistry, Northwestern University, Evanston, Illinois 60208, United States.

ORCID ID - orcid.org/0000-0002-4449-9566

Email: jkalow@northwestern.edu

\section{Authors}

Pradipta Das - Department of Chemistry, Northwestern University, Evanston, Illinois 60208, United States. ORCID ID - orcid.org/0000-0002-6530-8909

Eliot F. Woods - Department of Chemistry, Northwestern University, Evanston, Illinois 60208, United States. ORCID ID - orcid.org/0000-0003-3912-1195

Jack T. Ly - Air Force Research Laboratory, Materials and Manufacturing Directorate, Wright-Patterson Air Force Base, Dayton, Ohio 45433, United States.

UES Inc., Dayton, Ohio 45432, United States.

ORCID ID - orcid.org/0000-0001-9164-508X

Jack N. Olding - Applied Physics Graduate Program, Northwestern University, Evanston, Illinois 60208, United States.

ORCID ID - orcid.org/0000-0001-6907-5316

Kayla F. Presley - Air Force Research Laboratory, Materials and Manufacturing Directorate, Wright-Patterson Air Force Base, Dayton, Ohio 45433, United States.

UES Inc., Dayton, Ohio 45432, United States.

ORCID ID - orcid.org/0000-0001-9091-3214

Brennan Romanoff - Department of Physics, United States Air Force Academy, Colorado 80840, United States

Tod A. Grusenmeyer - Air Force Research Laboratory, Materials and Manufacturing Directorate, Wright-Patterson Air Force Base, Dayton, Ohio 45433, United States

ORCID ID - orcid.org/0000-0002-1842-056X

Emily A. Weiss - Department of Chemistry, Northwestern University, Evanston, Illinois 60208, United States.

Department of Material Science and Engineering, Northwestern University, Evanston, Illinois 60208, United States.

Applied Physics Graduate Program, Northwestern University, Evanston, Illinois 60208, United States.

ORCID ID - orcid.org/0000-0001-5834-463X 


\section{Notes}

The authors declare no competing financial interest.

\section{ACKNOWLEDGMENT}

This research was supported by funding from the American Chemical Society Petroleum Research Fund (58452-DNI4, P.D. and J.A.K.), the Air Force Office of Scientific Research Young Investigator Program (FA9550-18-1-0159, E.F.W., P.D., and J.A.K.), the AAAS Marion Milligan Mason Award (J.A.K.), and the Northwestern University Materials Research Science and Engineering Center (NSF DMR1720139, J.N.O. and E.A.W.). The work performed at the Air Force Research Laboratory was supported through contract FA8650-15-D5405 awarded to UES, Inc. and by Defense Advanced Research Projects Agency (DARPA) contract 140D6318C0019. Portions of this research were performed while Kayla F. Presley held an NRC Research Associateship award at the Air Force Research Laboratory. The authors thank Dr. Rafael Lopez-Arteaga for helpful comments and suggestions. This work made use of NMR and MS instrumentation at the Integrated Molecular Structure Education and Research Center (IMSERC) at Northwestern, which has received support from the NSF (NSF CHE9871268), the Soft and Hybrid Nanotechnology Experimental (SHyNE) Resource (NSF ECCS-1542205), the State of Illinois, and the International Institute for Nanotechnology.

\section{REFERENCES}

(1) Twilton, J.; Le, C.; Zhang, P.; Shaw, M. H.; Evans, R. W.; MacMillan, D. W. C. The Merger of Transition Metal and Photocatalysis. Nat. Rev. Chem. 2017, 1, 1 - 17.

(2) Bissember, A. C.; Lundgren, R. J.; Creutz, S. E.; Peters, J. C.; Fu, G. C. Transition-Metal-Catalyzed Alkylations of Amines with Alkyl Halides: Photoinduced, Copper-Catalyzed Couplings of Carbazoles. Angew. Chem. Int. Ed. 2013, 52, 5129 - 5133.

(3) Kainz, Q. M.; Matier, C. D.; Bartoszewicz, A.; Zultanski, S. L.; Peters, J. C.; Fu, G. C. Asymmetric Copper-Catalyzed C-N Cross-Couplings Induced by Visible Light. Science 2016, 351, $681-684$.

(4) Ahn, J. M.; Ratani, T. S.; Hannoun, K. I.; Fu, G. C.; Peters, J. C. Photoinduced, Copper-Catalyzed Alkylation of Amines: A Mechanistic Study of the Cross-Coupling of Carbazole with Alkyl Bromides. J. Am. Chem. Soc. 2017, 139, 12716 - 12723.

(5) Parasram, M.; Gevorgyan, V. Visible Light-Induced Transition Metal-Catalyzed Transformations: Beyond Conventional Photosensitizers. Chem. Soc. Rev. 2017, 46, 6227 - 6240.

(6) Chuentragool, P.; Kurandina, D.; Gevorgyan, V. Catalysis with Palladium Complexes Photoexcited by Visible Light. Angew. Chem. Int. Ed. 2019, 58 (34), 11586 - 11598.

(7) Crisenza, G. E. M.; Faraone, A.; Gandolfo, E.; Mazzarella, D.; Melchiorre, P. Catalytic Asymmetric C-C Cross-Couplings Enabled by Photoexcitation. Nat. Chem. 2021, 13, 575 - 580.

(8) Torres, G. M.; Liu, Y.; Arndtsen, B. A. A Dual Light-Driven Palladium Catalyst: Breaking the Barriers in Carbonylation Reactions. Science 2020, $368,318-323$.

(9) Dewanji, A.; Bülow, R. F.; Rueping, M. Photoredox/Nickel DualCatalyzed Reductive Cross Coupling of Aryl Halides Using an Organic Reducing Agent. Org. Lett. 2020, 22, 1611 - 1617.

(10) Cybularczyk-Cecotka, M.; Szczepanik, J.; Giedyk, M. Photocatalytic Strategies for the Activation of Organic Chlorides. Nat. Catal. 2020, 3, 872 $-886$.

(11) Fu, Y.; Huang, J.; Wu, Y.; Liu, X.; Zhong, F.; Wang, J. Biocatalytic Cross-Coupling of Aryl Halides with a Genetically Engineered Photosensitizer Artificial Dehalogenase.J. Am. Chem. Soc. 2021, 143, 617 -622 .

(12) Polites, V. C.; Badir, S. O.; Keess, S.; Jolit, A.; Molander, G. A. Nickel-Catalyzed Decarboxylative Cross-Coupling of Bicyclo[1.1.1]Pentyl Radicals Enabled by Electron Donor-Acceptor Complex Photoactivation. Org. Lett. 2021, 23, $4828-4833$.
(13) Yang, T.; Wei, Y.; Koh, M. J. Photoinduced Nickel-Catalyzed Deaminative Cross-Electrophile Coupling for $\mathrm{C}\left(\mathrm{sp}^{2}\right)-\mathrm{C}\left(\mathrm{sp}^{3}\right)$ and $\mathrm{C}\left(\mathrm{sp}^{3}\right)-$ $\mathrm{C}\left(\mathrm{sp}^{3}\right)$ Bond Formation. ACS Catal. 2021, 11,6519-6525.

(14) Romero, N. A.; Nicewicz, D. A. Organic Photoredox Catalysis. Chem. Rev. 2016, 116, 10075 - 10166.

(15) Sahoo, B.; Hopkinson, M. N.; Glorius, F. External-PhotocatalystFree Visible-Light-Mediated Synthesis of Indolizines. Angew. Chem. Int. Ed. 2015, 54, 15545 - 15549.

(16) Wang, D.; Cheng, C.; Wu, Q.; Wang, J.; Kang, Z.; Guo, X.; Wu, H.; Hao, E.; Jiao, L. Visible-Light Excitation of BODIPYs Enables SelfPromoted Radical Arylation at Their 3,5-Positions with Diazonium Salts. Org. Lett. 2019, 21, $5121-5125$.

(17) Wang, D.; Guo, X.; Wu, H.; Wu, Q.; Wang, H.; Zhang, X.; Hao, E.; Jiao, L. Visible Light Excitation of BODIPYs Enables Dehydrogenative Enamination at Their $\alpha$-Positions with Aliphatic Amines. J. Org. Chem. 2020, 85, 8360 - 8370 .

(18) Kancherla, R.; Muralirajan, K.; Sagadevan, A.; Rueping, M. Visible Light-Induced Excited-State Transition-Metal Catalysis. Trends Chem. 2019, 1, $510-523$.

(19) Zhang, C.; Zhao, J.; Wu, S.; Wang, Z.; Wu, W.; Ma, J.; Guo, S.; Huang, L. Intramolecular RET Enhanced Visible Light-Absorbing Bodipy Organic Triplet Photosensitizers and Application in Photooxidation and Triplet-Triplet Annihilation Upconversion. J. Am. Chem. Soc. 2013, 135, 10566 - 10578

(20) Li, W.; Xie, Z.; Jing, X. BODIPY Photocatalyzed Oxidation of Thioanisole under Visible Light. Catal. Commun. 2011, 16, 94 - 97.

(21) Huang, L.; Zhao, J.; Guo, S.; Zhang, C.; Ma, J. Bodipy Derivatives as Organic Triplet Photosensitizers for Aerobic Photoorganocatalytic Oxidative Coupling of Amines and Photooxidation of Dihydroxylnaphthalenes. J. Org. Chem. 2013, 78, 5627 - 5637.

(22) Wang, X.-F.; Yu, S.-S.; Wang, C.; Xue, D.; Xiao, J. BODIPY Catalyzed Amide Synthesis Promoted by BHT and Air under Visible Light. Org. Biomol. Chem. 2016, 14, 7028 - 7037.

(23) Wang, X.-Z.; Meng, Q.-Y.; Zhong, J.-J.; Gao, X.-W.; Lei, T.; Zhao, L.-M.; Li, Z.-J.; Chen, B.; Tung, C.-H.; Wu, L.-Z. The Singlet Excited State of BODIPY Promoted Aerobic Cross-Dehydrogenative-Coupling Reactions under Visible Light. Chem. Commun. 2015, 51, 11256 - 11259.

(24) Yang, L.; Huang, Z.; Li, G.; Zhang, W.; Cao, R.; Wang, C.; Xiao, J.; Xue, D. Synthesis of Phenols: Organophotoredox/Nickel Dual Catalytic Hydroxylation of Aryl Halides with Water. Angew. Chem. Int. Ed. 2018, 57, $1968-1972$.

(25) Magagnano, G.; Gualandi, A.; Marchini, M.; Mengozzi, L.; Ceroni, P.; Cozzi, P. G. Photocatalytic ATRA Reaction Promoted by Iodo-Bodipy and Sodium Ascorbate. Chem. Commun. 2017, 53, 1591 - 1594.

(26) Stafford, A.; Ahn, D.; Raulerson, E. K.; Chung, K.-Y.; Sun, K.; Cadena, D. M.; Forrister, E. M.; Yost, S. R.; Roberts, S. T.; Page, Z. A. Catalyst Halogenation Enables Rapid and Efficient Polymerizations with Visible to Far-Red Light. J. Am. Chem. Soc. 2020, 142, 14733 - 14742.

(27) Lu, P.; Chung, K.-Y.; Stafford, A.; Kiker, M.; Kafle, K.; Page, Z. A. Boron Dipyrromethene (BODIPY) in Polymer Chemistry. Polym. Chem. 2021, 12, $327-348$.

(28) Loudet, A.; Burgess, K. BODIPY Dyes and Their Derivatives: Syntheses and Spectroscopic Properties. Chem. Rev. 2007, 107, 4891 4932.

(29) Kamkaew, A.; Lim, S. H.; Lee, H. B.; Kiew, L. V.; Chung, L. Y.; Burgess, K. BODIPY Dyes in Photodynamic Therapy. Chem Soc Rev 2013, $42,77-88$.

(30) Zhao, J.; Xu, K.; Yang, W.; Wang, Z.; Zhong, F. The Triplet Excited State of Bodipy: Formation, Modulation and Application. Chem. Soc. Rev. 2015, 44, $8904-8939$.

(31) Chen, K.; Dong, Y.; Zhao, X.; Imran, M.; Tang, G.; Zhao, J.; Liu, Q. Bodipy Derivatives as Triplet Photosensitizers and the Related Intersystem Crossing Mechanisms. Front. Chem. 2019, 7, 821.

(32) Lu, H.; Mack, J.; Yang, Y.; Shen, Z. Structural Modification Strategies for the Rational Design of Red/NIR Region BODIPYs. Chem Soc Rev2014, 43, 4778 - 4823.

(33) Wu, W.; Guo, H.; Wu, W.; Ji, S.; Zhao, J. Organic Triplet Sensitizer Library Derived from a Single Chromophore (BODIPY) with Long-Lived 
Triplet Excited State for Triplet-Triplet Annihilation Based Upconversion. J. Org. Chem. 2011, 76, 7056-7064.

(34) Thompson, B. L.; Heiden, Z. Redox Chemistry of BODIPY Dyes in BODIPY Dyes - A Privilege Molecular Scaffold with Tunable Properties; 2019.

(35) Miao, W.; Yu, C.; Hao, E.; Jiao, L. Functionalized BODIPYs as Fluorescent Molecular Rotors for Viscosity Detection. Front. Chem. 2019, 7,825

(36) Kowada, T.; Maeda, H.; Kikuchi, K. BODIPY-Based Probes for the Fluorescence Imaging of Biomolecules in Living Cells. Chem. Soc. Rev. 2015, 44, 4953 - 4972.

(37) Yogo, T.; Urano, Y.; Ishitsuka, Y.; Maniwa, F.; Nagano, T. Highly Efficient and Photostable Photosensitizer Based on BODIPY Chromophore. J. Am. Chem. Soc. 2005, 127, 12162 - 12163.

(38) Yuster, P.; Weissman, S. I. Effects of Perturbations on Phosphorescence: Luminescence of Metal Organic Complexes. J. Chem. Phys. 1949, 17, 1182 - 1188.

(39) McClure, D. S. Triplet-Singlet Transitions in Organic Molecules. Lifetime Measurements of the Triplet State. J. Chem. Phys. 1949, 17, $905-$ 913.

(40) Ly, J. T.; Presley, K. F.; Cooper, T. M.; Baldwin, L. A.; Dalton, M. J.; Grusenmeyer, T. A. Impact of Iodine Loading and Substitution Position on Intersystem Crossing Efficiency in a Series of Ten Methylated- Meso Phenyl-BODIPY Dyes. Phys. Chem. Chem. Phys. 2021, 23, 12033 - 12044.

(41) Rey, Y. P.; Abradelo, D. G.; Santschi, N.; Strassert, C. A.; Gilmour, R. Quantitative Profiling of the Heavy-Atom Effect in BODIPY Dyes: Correlating Initial Rates, Atomic Numbers, and ${ }^{1} \mathrm{O}_{2}$ Quantum Yields: Quantitative Profiling of the Heavy-Atom Effect in BODIPY Dyes: Correlating Initial Rates, Atomic Numbers, and ${ }^{1} \mathrm{O}_{2}$ Quantum Yields. Eur.J. Org. Chem. 2017, 2017, $2170-2178$.

(42) Kee, H. L.; Kirmaier, C.; Yu, L.; Thamyongkit, P.; Youngblood, W. J.; Calder, M. E.; Ramos, L.; Noll, B. C.; Bocian, D. F.; Scheidt, W. R.; Birge, R. R.; Lindsey, J. S.; Holten, D. Structural Control of the Photodynamics of Boron-Dipyrrin Complexes. J. Phys. Chem. B 2005, 109, 20433 - 20443.

(43) Li, W.; Li, L.; Xiao, H.; Qi, R.; Huang, Y.; Xie, Z.; Jing, X.; Zhang, H. Iodo-BODIPY: A Visible-Light-Driven, Highly Efficient and Photostable Metal-Free Organic Photocatalyst. RSC Adv. 2013, 3, 13417 - 13421.

(44) Tsou, T. T.; Kochi, J. K. Reductive Coupling of Organometals Induced by Oxidation. Detection of Metastable Paramagnetic Intermediates. J. Am. Chem. Soc. 1978, 100, 1634 - 1635.

(45) Tsou, T. T.; Kochi, J. K. Mechanism of Oxidative Addition. Reaction of Nickel(0) Complexes with Aromatic Halides. J. Am. Chem. Soc. 1979, 101, $6319-6332$.

(46) Tsou, T. T.; Kochi, J. K. Mechanism of Biaryl Synthesis with Nickel Complexes. J. Am. Chem. Soc. 1979, 101, 7547 - 7560.

(47) Diccianni, J. B.; Diao, T. Mechanisms of Nickel-Catalyzed CrossCoupling Reactions. Trends Chem. 2019, 1, 830 - 844.

(48) Ren, H.; Li, G.-F.; Zhu, B.; Lv, X.-D.; Yao, L.-S.; Wang, X.-L.; Su, Z.M.; Guan, W. How Does Iridium(III) Photocatalyst Regulate Nickel(II) Catalyst in Metallaphotoredox-Catalyzed C-S Cross-Coupling? Theoretical and Experimental Insights. ACS Catal. 2019, 9, 3858-3865.

(49) Corcoran, E. B.; Pirnot, M. T.; Lin, S.; Dreher, S. D.; DiRocco, D. A.; Davies, I. W.; Buchwald, S. L.; MacMillan, D. W. C. Aryl Amination Using Ligand-Free Ni(II) Salts and Photoredox Catalysis. Science 2016, $353,279-283$.

(50) Terrett, J. A.; Cuthbertson, J. D.; Shurtleff, V.W.; MacMillan, D. W. C. Switching on Elusive Organometallic Mechanisms with Photoredox Catalysis. Nature 2015, 524, 330 - 334.

(51) Zhu, B.; Yan, L.-K.; Geng, Y.; Ren, H.; Guan, W.; Su, Z.-M. Ir ${ }^{\mathrm{III}} / \mathrm{Ni}$ II -Metallaphotoredox Catalysis: The Oxidation State Modulation Mechanism versus the Radical Mechanism. Chem. Commun. 2018, 54, $5968-5971$.

(52) Shields, B. J.; Kudisch, B.; Scholes, G. D.; Doyle, A. G. Long-Lived Charge-Transfer States of Nickel(II) Aryl Halide Complexes Facilitate Bimolecular Photoinduced Electron Transfer. J. Am. Chem. Soc. 2018, 140, 3035 - 3039.

(53) Sun, R.; Qin, Y.; Nocera, D. G. General Paradigm in Photoredox Nickel-Catalyzed Cross-Coupling Allows for Light-Free Access to Reactivity. Angew. Chem. Int. Ed. 2020, 59, 9527 - 9533.
(54) Sun, R.; Qin, Y.; Ruccolo, S.; Schnedermann, C.; Costentin, C.; Nocera, D. G. Elucidation of a Redox-Mediated Reaction Cycle for NickelCatalyzed Cross Coupling. J. Am. Chem. Soc. 2019, 141, 89 - 93.

(55) $4000 \mathrm{~K}$ white LEDs, composed of a blue LED and yellow/red phosphors, have significantly less intensity at $525 \mathrm{~nm}$ then the green $525 \mathrm{~nm}$ LEDs. See Figure S13 for emission profile.

(56) Almond-Thynne, J.; Blakemore, D. C.; Pryde, D. C.; Spivey, A. C. Site-Selective Suzuki-Miyaura Coupling of Heteroaryl Halides Understanding the Trends for Pharmaceutically Important Classes. Chem. Sci. 2017, 8, $40-62$.

(57) Legault, C. Y.; Garcia, Y.; Merlic, C. A.; Houk, K. N. Origin of Regioselectivity in Palladium-Catalyzed Cross-Coupling Reactions of Polyhalogenated Heterocycles. J. Am. Chem. Soc. 2007, 129, 12664 12665.

(58) Marshall, J. L.; O’Neal, N. J.; Zakharov, L. N.; Haley, M. M. Synthesis and Characterization of Two Unsymmetrical Indenofluorene Analogues: Benzo[5,6]- $s$-Indaceno[1,2-b]Thiophene and Benzo[5,6]-sIndaceno[2,1-b] Thiophene. J. Org. Chem. 2016, 81, $3674-3680$.

(59) Dobrounig, P.; Trobe, M.; Breinbauer, R. Sequential and Iterative Pd-Catalyzed Cross-Coupling Reactions in Organic Synthesis. Monatshefte Für Chem. - Chem. Mon. 2017, 148, 3 - 35.

(60) Poelma, S. O.; Burnett, G. L.; Discekici, E. H.; Mattson, K. M.; Treat, N. J.; Luo, Y.; Hudson, Z. M.; Shankel, S. L.; Clark, P. G.; Kramer, J. W.; Hawker, C. J.; Read de Alaniz, J. Chemoselective Radical Dehalogenation and $\mathrm{C}-\mathrm{C}$ Bond Formation on Aryl Halide Substrates Using Organic Photoredox Catalysts. J. Org. Chem. 2016, 81, 7155 - 7160.

(61) Ghosh, I.; König, B. Chromoselective Photocatalysis: Controlled Bond Activation through Light-Color Regulation of Redox Potentials. Angew. Chem. Int. Ed. 2016, 55, 7676 - 7679.

(62) Seo, T.; Kubota, K.; Ito, H. Selective Mechanochemical Monoarylation of Unbiased Dibromoarenes by in Situ Crystallization. J. Am. Chem. Soc. 2020, 142, 9884 - 9889.

(63) Ulrich, G.; Barsella, A.; Boeglin, A.; Niu, S.; Ziessel, R. BODIPYBridged Push-Pull Chromophores for Nonlinear Optical Applications. ChemPhysChem 2014, 15, 2693 - 2700.

(64) Bonnier, C.; Machin, D. D.; Abdi, O.; Koivisto, B. D. Manipulating Non-Innocent $\pi$-Spacers: The Challenges of Using 2,6-Disubstituted BODIPY Cores within Donor-Acceptor Light-Harvesting Motifs. Org. Biomol. Chem. 2013, 11, 3756 - 3760.

(65) Bonardi, L.; Ulrich, G.; Ziessel, R. Tailoring the Properties of Boron-Dipyrromethene Dyes with Acetylenic Functions at the 2,6,8 and 4B Substitution Positions. Org. Lett. 2008, 10, 2183 - 2186.

(66) Hayashi, Y.; Yamaguchi, S.; Cha, W. Y.; Kim, D.; Shinokubo, H. Synthesis of Directly Connected BODIPY Oligomers through SuzukiMiyaura Coupling. Org. Lett. 2011, 13, 2992 - 2995.

(67) Cakmak, Y.; Akkaya, E. U. Phenylethynyl-BODIPY Oligomers: Bright Dyes and Fluorescent Building Blocks. Org. Lett. 2009, 11, 85 - 88.

(68) Niu, S.; Ulrich, G.; Retailleau, P.; Ziessel, R. BODIPY-Bridged Push-Pull Chromophores: Optical and Electrochemical Properties. Tetrahedron Lett. 2011, 52, 4848 - 4853.

(69) Karlsson, J. K. G.; Harriman, A. Origin of the Red-Shifted Optical Spectra Recorded for Aza-BODIPY Dyes. J. Phys. Chem. A 2016, 120, 2537 $-2546$.

(70) Hall, M. J.; McDonnell, S. O.; Killoran, J.; O’Shea, D. F. A Modular Synthesis of Unsymmetrical Tetraarylazadipyrromethenes. J. Org. Chem. 2005, 70,5571- 5578 .

(71) Sathyamoorthi, G.; Soong, M.-L.; Ross, T. W.; Boyer, J. H. Fluorescent Tricyclic $\beta$-Azavinamidine-BF2 Complexes. Heteroat. Chem. 1993, 4, $603-608$.

(72) Adarsh, N.; Avirah, R. R.; Ramaiah, D. Tuning Photosensitized Singlet Oxygen Generation Efficiency of Novel Aza-BODIPY Dyes. Org. Lett. 2010, 12, 5720 - 5723.

(73) Gorman, A.; Killoran, J.; O’Shea, C.; Kenna, T.; Gallagher, W. M.; O'Shea, D. F. In Vitro Demonstration of the Heavy-Atom Effect for Photodynamic Therapy. J. Am. Chem. Soc. 2004, 126, 10619 - 10631.

(74) Lin, Z.; Kohn, A. W.; Van Voorhis, T. Toward Prediction of Nonradiative Decay Pathways in Organic Compounds II: Two Internal Conversion Channels in BODIPYs. J. Phys. Chem. C 2020, 124, 3925 3938. 
(75) Li, F.; Yang, S. I.; Ciringh, Y.; Seth, J.; Martin, C. H.; Singh, D. L.; Kim, D.; Birge, R. R.; Bocian, D. F.; Holten, D.; Lindsey, J. S. Design, Synthesis, and Photodynamics of Light-Harvesting Arrays Comprised of a Porphyrin and One, Two, or Eight Boron-Dipyrrin Accessory Pigments. J. Am. Chem. Soc. 1998, 120, $10001-10017$.

(76) Bahaidarah, E.; Harriman, A.; Stachelek, P.; Rihn, S.; Heyer, E.; Ziessel, R. Fluorescent Molecular Rotors Based on the BODIPY Motif: Effect of Remote Substituents. Photochem. Photobiol. Sci. 2014, 13, 1397 1401.
(77) Lou, Z.; Hou, Y.; Chen, K.; Zhao, J.; Ji, S.; Zhong, F.; Dede, Y.; Dick, B. Different Quenching Effect of Intramolecular Rotation on the Singlet and Triplet Excited States of Bodipy. J. Phys. Chem. C2018, 122, 185 - 193.

(78) Karanjit, S.; Kashihara, M.; Nakayama, A.; Shrestha, L. K.; Ariga, K.; Namba, K. Highly Active and Reusable Hydrotalcite-Supported Pd(0) Catalyst for Suzuki Coupling Reactions of Aryl Bromides and Chlorides. Tetrahedron 2018, 74, 948 - 954.

(79) Welin, E. R.; Le, C.; Arias-Rotondo, D. M.; McCusker, J. K.; MacMillan, D. W. C. Photosensitized, Energy Transfer-Mediated Organometallic Catalysis through Electronically Excited Nickel(II). Science 2017, 355, $380-385$. 
TOC graphic

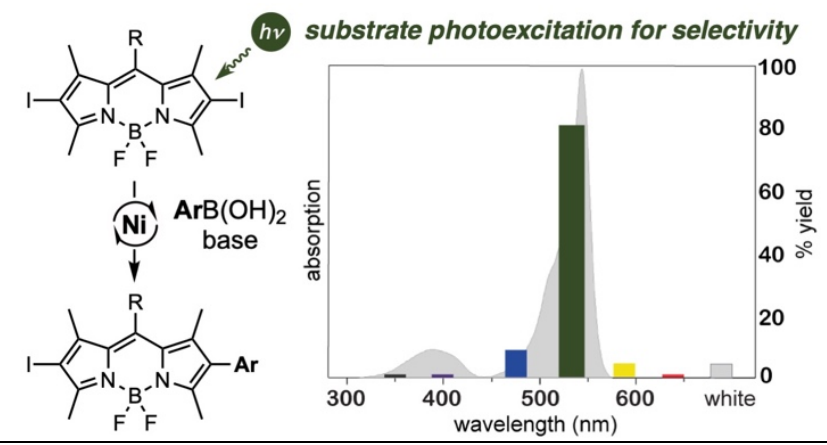

